\title{
Recent Trends in the Development of Benzimidazole Hybrid Derivatives and Their Antimalarial Activities
}

\author{
Waikhom Somraj Singh, Bikash Debnath, Kuntal Manna* \\ Natural cum Advance Synthetic Lab, Department of Pharmacy, Tripura University, Suryamaninagar, Tripura-799022, India \\ E-mail:k_manna2002@yahoo.com
}

Received: 12 April 2021; Revised: 7 June 2021; Accepted: 24 June 2021

\begin{abstract}
A parasite of the Plasmodium species initiates malaria. The parasite is transmitted to communities through the bite of an infected mosquito. Malarial resistance towards the commonly used antimalarial agents is a genuine human health problem. Benzimidazole derivatives exhibit a wide range of antimalarial activities against Plasmodium falciparum (P. falciparum) strain. The present review has summarized the antimalarial activity of benzimidazole hybrid derivatives and described its structural activity relationship (SAR) and quantitative structural-activity relationship (QSAR) model. A total of 14 papers were systematically reviewed. The literature survey has revealed that novel benzimidazole hybrid derivatives diminished the P. falciparum activity in the liver and gametocyte stages and inhibited heme synthesis and $\beta$-hematin formation. The QSAR models explain imminent antimalarial agent's growth through multiple linear regression (MLR) and artificial neural networks (ANN).
\end{abstract}

Keywords: Plasmodium falciparum, benzimidazole, drug resistance, QSAR, antimalarial activity

\section{Introduction}

Parasites triggered malaria among people by bites of female Anopheles mosquitoes. There are five parasites reported, namely Plasmodium falciparum (P. falciparum), Plasmodium vivax (P. vivax), Plasmodium malariae ( $P$. malariae), Plasmodium ovale (P. ovale), and Plasmodium knowlesi (P. knowlesi). The cycle of malaria consists of human and mosquito (Anopheles) hosts. ${ }^{1}$ Especially accounts of more severe mortality and morbidity in more than 100 countries have been widespread and most probably affected tropical areas of Asia, Latin America, and Africa. ${ }^{2,3}$ In 2015, 214 million clinical cases and 438,000 people died of malaria. ${ }^{4}$ In 2016, the World Health Organization (WHO) reported 216 million clinical issues and 445,000 deaths due to malaria. ${ }^{5}$ In 2017, WHO stated about 219 million malaria cases in 87 countries and estimated death of 435,000 peoples. ${ }^{6}$ According to WHO, there is no substantial improvement in clinical instances and decease caused by malaria from the World malaria report 2018. ${ }^{7}$ To control malaria, WHO inaugurated the Global Malaria Eradication Programme using dichlorodiphenyltrichloroethane (DDT) along with the chloroquine treatment. ${ }^{8}$ In the early 1820 s, antimalarial drugs have been discovered and marketed (Figure 1). ${ }^{9}$ Malaria vectors are resistant to insecticides, and chemotherapy/chemoprophylaxis has remained as combat against malaria. Resistant developed by the malaria vectors is seriously impeded to the first-line antimalarial drug's chloroquine (CQ) and sulfadoxine-pyrimethamine (SP) as well as second-line antimalarial drugs. Artemisinin-based combination chemotherapy (Figure 2) reduced the death rate, but later on, artemisinin resistance was also reported. ${ }^{10-13}$

Copyright (C2021 Kuntal Manna, et al.

DOI: https://doi.org/10.37256/fce.222021867

This is an open-access article distributed under a CC BY license

(Creative Commons Attribution 4.0 International License)

https://creativecommons.org/licenses/by/4.0/ 
The increase of resistance by mosquito vectors against antimalarial drugs lures serious attention to develop a new chemical entity that attenuates malaria problems. These will be the preliminary development to overcome malaria vector resistance. Benzimidazole (Figure 3), chemically $1-H$-benzo $[d]$ imidazole, is regarded as a critical pharmacologically active compound that possesses a wide range of biological activities. Benzimidazole exhibits an essential class for synthesizing various substitutes through structural modification by nucleophilic and cyclo-condensation reactions to fabricate suitable drugs/drug candidates. ${ }^{14-18}$ Substituted benzimidazole derivatives possess potent and pertinent activity by inhibiting intraerythrocytic asexual blood stages and the transmissible gametocyte stages of $P$. falciparum as well as potent plasmodium plasmepsin enzyme inhibitors. ${ }^{19,20}$ The quantitative structure-activity relationship (QSAR) model calculates binding affinity and interaction using multiple linear regression analysis (MLRA), topological and geometric descriptors, total energy, and the highest occupied molecular orbital associated with pharmacological deeds or assets of benzimidazole scaffolds. ${ }^{21-23}$ The novelty of the present work is the summarization of a recent study to elaborate the antimalarial activity of benzimidazole hybrid derivatives against antimalarial drug-resistant developed by the $P$. falciparum strain along with their structural-activity relationships.<smiles>C=c1/c(=C/c2ccc(Cl)cc2)c2cc(Cl)ccc2c2c(C(O)N(CCCC)CCCC)cc(Cl)cc12</smiles>
(artemether and lumefantrine)<smiles>COC(CC1CCCCN1)c1cc(C(F)(F)F)nc2c(C(F)(F)F)cccc12</smiles><smiles>O=C1C(=O)c2ccccc2C(O)=C1C1CCC(c2ccc(Cl)cc2)CC1</smiles>

Atovaquone<smiles>O=C1C(=O)c2ccccc2C(O)=C1C1CCC(c2ccc(Cl)cc2)CC1</smiles><smiles>CC(C)/N=C(N)\N=C(\N)Nc1ccc(Cl)cc1</smiles>

Malarone (Atovaquone-proguanil hydrochloride mixt)<smiles>C[C@H]1c2cccc(O)c2C(=O)C2=C(O)[C@]3(O)C(=O)C(C(N)=O)=C(O)[C@H](N(C)C)[C@]3(C)[C@H](O)[C@]21C</smiles>

Doxycycline hyclate<smiles>CCC[C@@H]1C[C@@H](C(=O)N[C@H]([C@H](C)Cl)[C@H]2O[C@H](SC)[C@@H](O)[C@H]2O)N(C)C1</smiles><smiles>CCN(CC)CCCC(C)Nc1ccnc2cc(Cl)ccc12</smiles>

chloroquine<smiles>COc1cc(NC(C)CCCN)c2ncccc2c1</smiles>

Primaquine<smiles>CCN(CCO)CCCC(C)Nc1ccnc2cc(Cl)ccc12</smiles>

Hydroxychloroquine

Figure 1. Marketed antimalarial drugs 
<smiles>C[C@H]1CC[C@H]2[C@@H](C)[C@H](OC(=O)CCC(=O)O)O[C@@H]3O[C@@]4(C)CCC1[C@@]23OO4</smiles>

Artesunate<smiles>CCCCN(CCCC)CC(O)c1cc(Cl)cc2c1-c1ccc(Cl)cc1/C2=C\c1ccc(Cl)cc1</smiles>

Lumefantrine<smiles>CCc1nc(N)nc(N)c1-c1ccc(Cl)cc1</smiles>

Sulfadoxine-Pyrimethamine (SP)/Fansidar<smiles>CCN(CC)Cc1cc(Nc2ccnc3cc(Cl)ccc23)ccc1O</smiles>

Amodiaquine

Figure 2. Artemisinin-based combination chemotherapy drugs

\section{Benzimidazole derivatives against antimalarial drugs resistant}

Singh et al. synthesized a novel pyrido[1,2-a]benzimidazole derivatives. Compounds $\mathbf{3} \mathbf{a}_{\mathbf{1}}$ and $\mathbf{3} \mathbf{a}_{\mathbf{2}}$ (Figure 3 ) exhibited the most active activity against chloroquine-sensitive (CQS PfNF54) strain in vivo in the mouse Plasmodium berghei $\left(P\right.$. berghei) model with $\mathrm{IC}_{50}, P f \mathrm{NF} 54=0.02 \mu \mathrm{M} ;$ Pf $\left.\mathrm{K} 1=0.02 \mu \mathrm{M}\right)\left(\mathbf{3 a}_{1}\right)$ and $\mathrm{IC}_{50}, P f \mathrm{NF} 54=0.03 \mu \mathrm{M} ;$ Pf $\mathrm{K} 1=0.04 \mu \mathrm{M}\left(\mathbf{3 a}_{2}\right)$. The synthesized compounds were then further studied for cytotoxicity activity in the rodent $P$. berghei against mammalian Chinese hamster ovary $(\mathrm{CHO})$ cell lines for the chloroquine multidrug-resistant $P f \mathrm{~K} 1$ strain in vivo. Compounds $\mathbf{3} \mathbf{a}_{1}$ and $\mathbf{3} \mathbf{a}_{2}$ diminished the activity of the parasite in the liver and gametocyte stages; were stable metabolically and well absorbed orally in the tested model. SAR studies also aided a positive point in finding the physicochemical evaluation and microsomal stability studies with substitution on the benzimidazole phenyl in vitro activity against $P$. falciparum. ${ }^{24}$

Sharma et al. synthesized benzimidazole acrylonitrile hybrids derivatives by condensing the 2-cyanomethyl benzimidazole with corresponding substituted aldehydes. The synthesized compounds were tested against chloroquinesensitive (3D7) and resistant (RKL9) strains in vitro. Among the synthesized compounds $\mathbf{3 b}_{1}\left(\mathrm{IC}_{50} 3 \mathrm{D} 7=0.69 \mu \mathrm{M}\right.$, RKL9 $=01.60 \mu \mathrm{M}), \mathbf{3 b}_{2}\left(\mathrm{IC}_{50} 3 \mathrm{D} 7=1.69 \mu \mathrm{M}, \mathrm{RKL} 9=14.36 \mu \mathrm{M}\right)$ and $\mathbf{3 b}_{3}\left(\mathrm{IC}_{50} 3 \mathrm{D} 7=1.61 \mu \mathrm{M}, \mathrm{RKL} 9=5.46 \mu \mathrm{M}\right)$ (Figure 3) showed most potent antimalarial activity. These compounds showed tolerable cytotoxicity limits and active inhibitory activity against falcipain-2 and hemozoin formation. A docking study was done on PDB ID: 3BPF. The result showed that the binding and molecular dynamic (MD) simulation exhibited the protein-ligand complex of synthesized compounds through silico studies. There are three subsites of enzymes, namely S1, S2, and S3. Synthesized benzimidazole acrylonitrile compounds entirely interacted with the amino acids constituting subsite S2, viz. Trp43, Leu84, Ile85, Ser149, Ala175, and Gly83 showed identical configuration at subsite S2 as E64 (cocrystallized ligand of PDB ID: 3BPF). At subsite S1, the ligand also interacts with Cys42 and His174. But the synthesized compound unbinds with the amino acids Asn71 and Tyr78 of subsite S3. The heme-binding studies identify that compound $\mathbf{3 b}_{\mathbf{1}}$ binds at basic $\mathrm{pH} 7.4$ and acidic $\mathrm{pH}$ 5.6. Compound $\mathbf{3 b}_{\mathbf{1}}$ also binds to heme [Fe(III) PPIX] and inhibits aggregation to $\beta$-hematin. $\mathbf{3} \mathbf{b}_{\mathbf{1}}$ inhibited hemozoin formation by falcipain-2 (FP-2) enzyme binding. SAR study revealed that the substitution of 
a methoxy group at 2, 3, 4, and 5 positions was favorable for the antimalarial activity but not more than two methoxy group's substitution. They reported that substituting a methoxy group at 3-position is the best for antimalarial activity, followed by 3,5-dimethoxy, 3,4-dimethoxy, and 2,4-dimethoxy. Decrease/loss of activity was observed with replacement of $3-\mathrm{OCH}_{3}$ group with other electron-donating groups with high electronegative atoms like -OH group. ${ }^{25}$

Romero et al. synthesized benzimidazole-5-carboxamide derivatives ( $\mathbf{3 c}_{\mathbf{1 - 7}}$ ) (Figure 3) and were evaluated against antimalarial activity in mice $P$. berghei, which was infected with ANKA chloroquine-sensitive strain. Among the synthesized compounds $\mathbf{3} \mathbf{c}_{\mathbf{1}}\left(\% \mathrm{I} \beta \mathrm{HF}( \pm \mathrm{SD})^{\mathrm{a}}=76.45 \pm 0.03\right), \mathbf{3} \mathbf{c}_{\mathbf{3}}\left(\% \mathrm{I} \beta \mathrm{HF}( \pm \mathrm{SD})^{\mathrm{a}}=86.49 \pm 0.044\right), \mathbf{3} \mathbf{c}_{4}\left(\% \mathrm{I} \beta \mathrm{HF}( \pm \mathrm{SD})^{\mathrm{a}}\right.$ $=85.62 \pm 0.066), \mathbf{3} \mathbf{c}_{5}\left(\% \mathrm{I} \beta \mathrm{HF}( \pm \mathrm{SD})^{\mathrm{a}}=77.15 \pm 0.053\right), \mathbf{3} \mathbf{c}_{\mathbf{6}}\left(\% \mathrm{I} \beta \mathrm{HF}( \pm \mathrm{SD})^{\mathrm{a}}=82.51 \pm 0.001\right)$ and $\mathbf{3} \mathbf{c}_{7}\left(\% \mathrm{I} \beta \mathrm{HF}( \pm \mathrm{SD})^{\mathrm{a}}\right.$ $=74.19 \pm 0.116$ ) showed potent $\beta$-hematin formation blockers (Table 1). And the compounds $\mathbf{3} \mathbf{c}_{\mathbf{1}}$ and $\mathbf{3} \mathbf{c}_{\mathbf{3}}$ showed potent antimalarial activity compared with standard drug chloroquine. Compounds $\mathbf{3} \mathbf{c}_{\mathbf{2}}$ showed most potent cytotoxicity activity against two human cancer cell lines, namely Jurkat E6.1 $\left(\mathrm{IC}_{50}( \pm \mathrm{SD}) 24 \mathrm{~h}=7.05 \pm 0.60 *\right)$, and $\mathrm{HL} 60\left(\mathrm{IC}_{50}( \pm\right.$ SD) $24 \mathrm{~h}=2.95 \pm 0.28 *)(* \mathrm{p}<0.01$ compared to doxorubicin $)$ and in fresh human lymphocytes among the synthesized compounds. This cytotoxic activity could be due to the inhibition of heme synthesis, or the inhibition of lysosome induces autophagy. SAR study reveals that the presence of significant antiplasmodial activity of benzimidazole-5carboxamide derivatives may be due to $\pi-\pi$ stacking interaction with the porphyrin ring system, in the benzimidazole ring, the presence of 5-nitrofuran-2-yl or a 5-nitrothyophen-2-yl on the 2-position, and a replacement pattern of 2, 4 or 3, 4 with lipophilic groups in a phenylcarboxamide in position $5 .^{26}$

Table 1. Percentage of inhibition of $\beta$-hematin formation $(\% \mathrm{I} \beta \mathrm{HF})^{24}$

\begin{tabular}{|c|c|c|c|c|c|}
\hline Comp. No. & $\mathrm{R}$ & $\% \mathrm{I} \beta \mathrm{HF}( \pm \mathrm{SD})^{\mathrm{a}}$ & $\% \mathrm{P}^{\mathrm{b}}( \pm \mathrm{SD})^{\mathrm{a}}$ & $\mathrm{Sd}^{\mathrm{c}}( \pm \mathrm{SD})^{\mathrm{a}}$ & Survival $^{\mathrm{d}}$ \\
\hline $3 c_{1}$ & $\mathrm{X}=\mathrm{O}, \mathrm{R}=\mathrm{H}$ & $76.45 \pm 0.03$ & $4.02 \pm 0.45$ & $17.00 \pm 1.26$ & $0 / 6$ \\
\hline $3 c_{2}$ & $\mathrm{X}=\mathrm{O}, \mathrm{R}=2,3,4-\mathrm{CH}_{3}$ & $10.38 \pm 0.16$ & - & - & $0 / 6$ \\
\hline $3 c_{3}$ & $\mathrm{X}=\mathrm{O}, \mathrm{R}=2,4-\mathrm{CH}_{3}$ & $86.49 \pm 0.044$ & $3.05 \pm 0.09$ & $20.20 \pm 1.95$ & $0 / 6$ \\
\hline $3 c_{4}$ & $\mathrm{X}=\mathrm{O}, \mathrm{R}=3,4-\mathrm{CH}_{3}$ & $85.62 \pm 0.066$ & $19.66 \pm 1.76$ & $8.80 \pm 1.53$ & $0 / 6$ \\
\hline $3 c_{5}$ & $\mathrm{X}=\mathrm{O}, \mathrm{R}=2-\mathrm{CH}_{3}$ & $88.74 \pm 0.008$ & $47.00 \pm 1.32$ & $10.61 \pm 1.14$ & $0 / 6$ \\
\hline $3 c_{6}$ & $\mathrm{X}=\mathrm{S}, \mathrm{R}=3,4-\mathrm{CH}_{3}$ & $82.515 \pm 0.001$ & $52.00 \pm 0.36$ & $8.80 \pm 0.14$ & $0 / 6$ \\
\hline $3 c_{7}$ & $\mathrm{X}=\mathrm{S}, \mathrm{R}=2-\mathrm{CH}_{3}$ & $95.58 \pm 0.081$ & $44.66 \pm 0.69$ & $10.20 \pm 1.98$ & $0 / 6$ \\
\hline $\mathrm{CQ}$ & - & $98.52 \pm 0.01$ & $0.80 \pm 0.037$ & $29.20 \pm 0.80$ & $5 / 6$ \\
\hline
\end{tabular}

P. berghei infected mice infection $\left(10 \mathrm{mg} / \mathrm{kg}^{-1}\right)$

CQ chloroquine, CISS control infected and treated with saline solution

$* p>0.05$ compared to chloroquine.

$* * \mathrm{p}<0.001$ compared to saline solution and chloroquine. $\mathrm{n}=6$

${ }^{\mathrm{a}} \mathrm{SD}$ : Standard deviation

${ }^{\mathrm{b}_{\%}} \mathrm{P}$ : Percentage of parasitemias

${ }^{\mathrm{c}} \mathrm{Sd}$ : Survival days

${ }^{\mathrm{d}}$ Number of mice that survived till day 30 post-infection/total mice in the group

Yadav et al. synthesized chalcone substituted derivatives by condensing chalcone and benzimidazole via the Claisen-Schmidt condensation method. Among the synthesized compounds, $\mathbf{3 d}_{\mathbf{1}}\left(\mathrm{IC}_{50}=2.86 \pm 0.06 \mu \mathrm{M}\right)$ (Figure 3 ) showed the most potent antimalarial activity against chloroquine-sensitive malaria parasite $P$. falciparum 3D7 strain and a chloroquine-resistant $P$. falciparum RKL 303 strain in vitro. They also reported that among the synthesized chalcone substituted derivatives consisting pyrrolidine $\left(\mathbf{3 d}_{\mathbf{2}}\right)\left(\mathrm{IC}_{50}=6.16 \pm 0.22 \mu \mathrm{M}\right)$, morpholine $\left(\mathbf{3 d}_{3}\right)\left(\mathrm{IC}_{50}=8.34 \pm 0.21 \mu \mathrm{M}\right)$ and 1, 2, 4-triazole $\left(\mathbf{3 d}_{4}\right)\left(\mathrm{IC}_{50}=10.07 \pm 0.22 \mu \mathrm{M}\right)$ in the place of benzimidazole have shown the insightful effect on parasites but lesser than compound $\mathbf{3} \mathbf{d}_{1}$. SAR study unveils that $\mathrm{IC}_{50}$ values of the compounds that the presence of dimethoxy groups at the 2 and 4 positions in benzaldehyde represented the most suitable positioning on binding to the enzyme active site. After this, they hypothesized that the formation of irreversible Michael addition with the interaction 
of His 67 of the enzyme with benzimidazole nitrogen resulted in a potential antimalarial activity. ${ }^{27}$

Ramachandran et al. synthesized the N-aryl-amino benzimidazole scaffold. Among the synthesized compounds, 3e $\left(\mathrm{IC}_{50}, \mathrm{NF} 54=0.036 \mu \mathrm{M} ; \mathrm{K} 1=0.059 \mu \mathrm{M}\right)$ (Figure 3$)$ showed significant activity against a fully sensitive (NF54) and multidrug-resistant (K1) strain of $P$. falciparum using an SYBR-Green based readout. In rat blood, this compound showed a half-life of $19 \mathrm{~h}$ and prolonged survival for 30 days more in a dose of $50 \mathrm{mg} / \mathrm{kg}$ in the $P$. berghei malariainfected. They reported that the synthesized aryl aminobenzimidazoles were evaluated in combination to find the resistance and demonstrate that the newer compounds can inhibit the P. falciparum at the sexual as well as liver stages. The 5-(trifluoromethyl) pyridin-2-amine is attached to the $2^{\text {nd }}$ position of benzimidazole, and methyl piperidine is substituted at the 5 -position of benzimidazole. ${ }^{28}$

Saify et al. synthesized 2-pyridine-2-yl-1H-benzimidazole derivatives $\left(\mathbf{3 f}_{1-3}\right)$ (Figure 3 ) and studied for $P$. falciparum plasmepsin II and human cathepsin D inhibitions through virtual screening. Synthesized benzimidazole derivatives with substitutions at the acetophenone ring showed potent enzyme inhibition at low micromolar ranges (2 48 $\mu \mathrm{M})$ and inhibited intraerythrocytic in culture P. falciparum. Among the synthesized compounds, $\mathbf{3 f}_{\mathbf{1}}\left(\mathrm{IC}_{50}=0.16 \pm 0.4\right.$ $\mu \mathrm{M})$ (Figure 3) showed potent antiplasmodial activity. They also reported that among the synthesized compounds, $\mathbf{3 f}_{2}$ $\left(\mathrm{IC}_{50}=0.7 \mu \mathrm{M}\right)$ and $\mathbf{3 f}_{3}\left(\mathrm{IC}_{50}=2.1 \mu \mathrm{M}\right)$ (Figure 3) showed antiplasmodial activity, respectively. Using FlexX ligand docking software (version 2.0), virtual screening studies revealed that the pyridine ring of benzimidazole compounds binds with S1 subsite and acetophenone moiety bind at S1-S3 active center of plasmepsin II comprehensive substrate, according to the plausible mode of binding. At the para position of acetophenone ring of compound $\mathbf{3} \mathbf{f}_{\mathbf{1}}$, the presence of phenyl group showed potent antimalarial activity, whereas in compound $\mathbf{3} \mathbf{f}_{2}$, presence of a chlorine atom and appearance of a nitro group at compound $\mathbf{3 f}_{3}{ }^{29}$

Ndakala et al. synthesized pyrido[1,2-a] benzimidazole derivatives and evaluated them for antiplasmodial activity and cytotoxicity. The pyrido[1,2-a] benzimidazole derivatives were synthesized by nucleophilic substitution with appropriate amine. Among the synthesized compounds, $\mathbf{3 g}$ (Figure 3) showed vigorous activities against the chloroquine drug-resistant $\mathrm{k} 1$ strain of $P$. falciparum in vitro. In $P$. berghei infected mice, $\mathbf{3 g}$ were administered sequentially intraperitoneal (ip) and oral (po). Compound 3g exhibit parasitemia with $>90 \%$ inhibition $\left(\mathrm{IC}_{50}=0.047 \mu \mathrm{M}\right.$ ) and $\sim 3.5$ times more potent than chloroquine along with the extension of the mean survival time and with negligible cytotoxicity against a mammalian (L-6) cell line. But in vivo study revealed that the synthesized compounds did not possess potential activity because of their metabolic stability due to the alkylamino side chain. There will be no significant effect in the alkyl chain length on in vitro antiplasmodial activity, but it varied only by one methylene unit. At the R1 position, substituting phenyl or monosubstituted in place of a $\mathrm{CF}_{3}$ group exhibit superior potency of up to 10 -fold. Then, the activity was further enhanced with the $\mathrm{R} 1$ aryl substituted with $\mathrm{CF}_{3}, \mathrm{Cl}$ or $\mathrm{F}$ group at 4-position. ${ }^{30}$

Toro et al. synthesized cyrhetrenyl and ferrocenyl benzimidazole derivatives through condensation-cyclization reaction. The synthesized compounds were evaluated against chloroquine susceptible strain (3D7) and chloroquine strain (W2) of P. falciparum. Among the synthesized compounds, Cyrhetrenyl $\left(\mathbf{3 h}_{\mathbf{1}}\right)$ (Figure 3) (1-Re- $\left(\mathrm{H}, \mathrm{NO}_{2}\right), \mathrm{IC}_{50}=$ 10.4-26.5 $\mu \mathrm{M})$ showed better antimalarial activity than ferrocenyl compounds $\left(\mathbf{3} \mathbf{h}_{2}\right)$ (Figure 3) $\left(\mathrm{IC}_{50}=23.9-48.0 \mu \mathrm{M}\right)$. The occurrence of this potent activity can be associated with the electron-withdrawing and well lipophilicity properties. The presence of a nitro group at the $5^{\text {th }}$ position of an organometallic benzimidazole compound showed an increase in antimalarial activity. ${ }^{31}$

Table 2. In vivo efficacy of synthesized derivatives (3i)

\begin{tabular}{cccc}
\hline & $\begin{array}{c}\text { Genz-667348 } \\
\mathrm{ED}_{50}\end{array}$ & $\begin{array}{c}\text { Genz-668857 } \\
\mathrm{ED}_{50}\end{array}$ & $\begin{array}{c}\text { Genz-669178 } \\
\mathrm{ED}_{50}\end{array}$ \\
\hline P. berghei $\mathrm{N}$ & 16.7 & 13.0 & 21.0 \\
P. berghei ANKA & 6.1 & $\mathrm{ND} *$ & $\mathrm{ND}$ \\
P. falciparum 3D70087/N9 & 5.3 & $\mathrm{ND}$ & $\mathrm{ND}$ \\
\hline ND*, not determined. & & &
\end{tabular}


Booker et al. synthesized N-alkyl-5-(1H-benzimidazol-1-yl) thiophene-2-carboxamide derivatives (3i) (Figure 3 ) and studied for dihydroorotate dehydrogenase (DHODH) antimalarial activity against $P$. falciparum, $P$. vivax, and $P$. berghei. The evaluation was done through in vitro high throughput screening, followed by medicinal chemistry programming. 3i showed potent antimalarial activity against 3D7 and Dd2 strains of $P$. falciparum, good tolerability, and oral exposure among the synthesized compounds. The efficacy was studied in vivo by orally administering compound $\mathbf{3 i}$ at a dose of 13-21 mg/kg/day twice a day, and after 4-days $\mathrm{ED}_{50}$ was observed, as shown in Table $2 .^{32}$

Camacho et al. synthesized N'-substituted-2-(5-nitrofuran or 5-nitrothiophen-2-yl)-3H-benzo[d]imidazole-5carbohydrazide derivatives $\left(\mathbf{3 j}_{\mathbf{1 - 6}}\right)$ (Figure 3 ). Among the synthesized compounds, $\mathbf{3} \mathbf{j}_{\mathbf{1}}\left(\mathrm{IC}_{50}=8.43 \mu \mathrm{M}\right), \mathbf{3} \mathbf{j}_{\mathbf{2}}\left(\mathrm{IC}_{50}=8.63\right.$ $\mu \mathrm{M}), \mathbf{3}_{\mathbf{4}}\left(\mathrm{IC}_{50}=13.13 \mu \mathrm{M}\right)$ and $\mathbf{3} \mathbf{j}_{\mathbf{5}}\left(\mathrm{IC}_{50}=9.56 \mu \mathrm{M}\right)$ possess inhibition of $\beta$-hematin formation. Compounds $\mathbf{3} \mathbf{j}_{\mathbf{1}}$ and $\mathbf{3} \mathbf{j}_{\mathbf{6}}$ $\left(\mathrm{IC}_{50}=11.10 \mu \mathrm{M}\right)$ showed the most potent antimalarial activities through inhibition of $\beta$-hematin formation in vitro and in vivo murine. Compound $\mathbf{3}_{3}\left(\mathrm{IC}_{50}=10.92 \mu \mathrm{M}\right)$ showed significant antitubercular activity against multidrug-resistant MDR-MTB strains compared to standard drugs rifampin. Among the synthesized compounds, $\mathbf{3} \mathbf{j}_{\mathbf{1}}, \mathbf{3} \mathbf{j}_{\mathbf{3}}$, and $\mathbf{3} \mathbf{j}_{\mathbf{6}}$ showed a good safety margin. ${ }^{2}$

Kamil Arfa et al. synthesized benzimidazole substituted phenacyl halide derivatives $\mathbf{3} \mathbf{k}_{\mathbf{1 - 3}}$ (Figure 3 ) and evaluated them against $P$. falciparum. Among the synthesized compounds, $\mathbf{3 k}_{\mathbf{1}}\left(\mathrm{IC}_{50}=0.019 \mu \mathrm{M}\right), \mathbf{3 k}_{\mathbf{2}}\left(\mathrm{IC}_{50}=0.034 \mu \mathrm{M}\right)$, and $\mathbf{3} \mathbf{k}_{\mathbf{3}}$ $\left(\mathrm{IC}_{50}=0.025 \mu \mathrm{M}\right)$ showed moderate inhibition against 3D7 P. falciparum strain after an incubation period of 72 hours. Those active compounds after their structural characterization revealed that the presence of monomethoxy, phenyl and dimethoxy groups might be liable for antimalarial activity. ${ }^{33}$

Keurulainen et al. synthesized 2-aminobenzimidazoles derivatives. Among the synthesized compound, 31 (Figure 3) showed potent antimalarial activity against $P$. falciparum with an $\mathrm{IC}_{50}$ value of $0.094 \mu \mathrm{M}$. The compounds were given orally in a single dose per day for four sequential days. It showed that parasitemia could dissipate the growth rate of parasites equivalent to antimalarial drugs such as dihydroartemisinin and piperaquine within two doses of the compounds. They reported that the compounds showed diminution ineffectiveness. ${ }^{34}$

Divatia et al. synthesized a series of (E)-2-[5-chloro-1-(1H-benzo[d]imidazol-2-yl)ethylidene] N-(substituted) hydrazine carbothioamide $\left(\mathbf{3 m}_{\mathbf{1 - 2 2}}\right)$ and (E)-2-[1-(1H-benzo[d]imidazol-2-yl)ethylidene] N-(substituted) hydrazine carbothioamide $\left(\mathbf{3 m}_{\mathbf{2 3 - 4 4}}\right)$ via the condensation of corresponding ketones with different thiosemicarbazides. Synthesized compounds were evaluated for antimalarial properties. Among the synthesized compounds $\mathbf{3 m}_{\mathbf{1 5}}\left(\mathrm{IC}_{50}=0.062 \mu \mathrm{M}\right), \mathbf{3 m}_{\mathbf{1 6}}$ $\left(\mathrm{IC}_{50}=0.004 \mu \mathrm{M}\right), \mathbf{3 m}_{\mathbf{1 7}}\left(\mathrm{IC}_{50}=0.025 \mu \mathrm{M}\right), \mathbf{3 m}_{\mathbf{1 8}}\left(\mathrm{IC}_{50}=0.070 \mu \mathrm{M}\right), \mathbf{3 m}_{\mathbf{1 9}}\left(\mathrm{IC}_{50}=0.012 \mu \mathrm{M}\right), \mathbf{3 m}_{\mathbf{2 7}}\left(\mathrm{IC}_{50}=0.182 \mu \mathrm{M}\right)$ and $\mathbf{3} \mathbf{m}_{\mathbf{3 0}}\left(\mathrm{IC}_{50}=0.216 \mu \mathrm{M}\right)$ exhibited good antimalarial activity in vitro. A SAR study revealed that thiosemicarbazides derivatives with electron-withdrawing groups such as chloro, fluoro, and iodo groups possess excellent potency. In contrast, moderate electron releasing groups such as methoxy group substitution exhibited good antimalarial activity. The presence of cyclohexyl and isopropyl groups is important for the antimalarial activity. ${ }^{35}$

\section{The advance of QSAR (quantitative structure-activity relationship) models in the development of antimalarial agents}

Quantitative structure-activity relationships (QSARs) practice chemical description with statistical models to describe the relationship between biological activity and molecular structure and prediction of activities by structural modification for leads generation.

Divatia et al. investigated the Quantitative Structure-Activity Relationship (QSAR) of synthesized thiosemicarbazone derivatives containing benzimidazole $\left(\mathbf{3 m}_{\mathbf{1 - 4 4}}\right)$. A Genetic Function Approximation (GFA) technique such as Quantum mechanical, topological, and geometric descriptors are the most dynamic molecular descriptors for the QSAR study. The correlation coefficient, LOF, $\mathrm{r}_{\mathrm{m}}^{2}$ and $\mathrm{r}_{\mathrm{cv}}^{2}$ values, showed a good result. The aftermaths of GFA revealed that the length of the molecule in Y-dimension, dipole moment, electrotopological count, and relative positive charge surface area for $\mathrm{CH}_{3}$ showed significant progress in P. falciparum. ${ }^{36}$

Worachartcheewan et al. synthesized 2'-aryl-substituted-1H, 1'H-[2, 5'] bisbenzimidazolyl-5-carboxamidines derivatives (3n) (Figure 3) and studied for antimalarial activity against $P$. falciparum. The synthesized compounds were analyzed QSAR by quantum chemical and molecular descriptors using B3LYP/6-31g (d) calculations and Dragon software. Other variables, such as total energy, the highest occupied molecular orbital, Moron autocorrelation-lag3/ 
weighted by atomic masses (MATS3m), Geary autocorrelation-lag8/weighted by atomic masses (GATS8m) and 3D-MoRSEsignal 11/weighted by atomic Sanderson electronegative (Mor11e) were used for the development of QSAR models. Besides the QSAR models, statistical parameters also explain imminent antimalarial agent growth through multiple linear regression (MLR) and artificial neural networks (ANN). Predicted models for MLR and ANN using leave-one-out cross-validation showed good result 0.9760 and 0.9821 of correlation coefficients of leave-one-out crossvalidation (RLOO-CV), 0.1301 and 0.1102 of root mean squared error of leave-one-out cross validation (RMSELOO$\mathrm{CV}), 0.9526$ and 0.9645 of productivity of leave-one-out cross-validation (Q2 LOO-CV), in anti-malarial activity against $P$. falciparum respectively. ${ }^{37}$

\section{Comparison of benzimidazole hybrid derivatives relating structures, SAR, and QSAR model with their related antimalarial activity}

Most studies evaluated laboratory strains of $P$. falciparum, chloroquine multidrug-resistant PfK1, chloroquinesensitive (3D7) and resistant (RKL9), ANKA chloroquine-sensitive strain, P. falciparum RKL 303, (NF54) and multidrug-resistant (K1) strain, P. falciparum plasmepsin II and human cathepsin D inhibitions, chloroquine drugresistant k1 strain, chloroquine susceptible strain (3D7) and chloroquine strain (W2), and inhibition of $\beta$-hematin formation. P. berghei was used on the animal-based model for malarial susceptibility, and synthesized benzimidazole was administered orally and intravenously., 24-37

Compounds $\mathbf{3} \mathbf{a}_{\mathbf{1 - 2}}$ and $\mathbf{3 g}$ have structural similarities, and both are pyrido[1,2-a] benzimidazole derivatives. Compound $\mathbf{3} \mathbf{a}_{\mathbf{1 - 2}}$ has a substitution at C-5, C-6, and C-7 position at benzimidazole ring while there was no substitution at C-5, C-6, and C-7 place at benzimidazole ring for $\mathbf{3 g}$ derivatives. Both the compounds have carbonitrile substitution.

Compounds $\mathbf{3} \mathbf{b}_{\mathbf{1 - 3}}$ and $\mathbf{3} \mathbf{l}$ have common substitution at $\mathrm{C}-2$ position at benzimidazole ring. $\mathbf{3 b}$ has a substitution of 2-cinnamonitrile at benzimidazole ring at $\mathrm{C}-2$ position while $\mathbf{3 1}$ has a 2-N-(3-aminopropyl) substitution 3,5-dichlorobenzamide at benzimidazole ring at $\mathrm{C}$-2. Compounds $\mathbf{3} \mathbf{c}_{\mathbf{1 - 7}}$ and $\mathbf{3} \mathbf{j}_{\mathbf{1 - 6}}$ have common substitution at $\mathrm{C}-2$ and C-5 of benzimidazole ring. Substitution of 2-nitrofuran $\left(\mathbf{3} \mathbf{c}_{\mathbf{1 - 5}}\right.$ and $\left.\mathbf{3} \mathbf{j}_{1-4}\right)$ and 2-nitrothiophene $\left(\mathbf{3 c}_{6-7}\right.$ and $\left.\mathbf{3} \mathbf{j}_{5-6}\right)$ are both at the C-2 position benzimidazole ring. At C-5 position substitution of N-phenylformamide on $\mathbf{3} \mathbf{c}_{1-7}$ and phenyl ring, the substitution of 3,4,5-trimethoxy, 2,4-dimethoxy, 3,4-dimethoxy, 2-methoxy were observed while in $\mathbf{3} \mathbf{j}_{\mathbf{1}}$, nitrofuran substitution was observed at the C-2 position of benzimidazole ring. At the C-5 position, carboxylic acid substitution was seen at the benzimidazole ring for $\mathbf{3} \mathbf{j}_{\mathbf{1}}$. While $\mathbf{3} \mathbf{j}_{\mathbf{2}-\mathbf{4}}$, the substitution of 2-nitrofuran was observed along with the substitution of phenyl and 3,4-methoxyphenyl at the C-5 position. $3 \mathbf{j}_{5-6}$ C-2 position, 2-nitrofuran was replaced with 2-nitrothiophene. At the C-5 position, 3,4-methoxyphenyl and 2-hydroxyl-2-naphthyl groups were substituted. Compound $\mathbf{3} \mathbf{d}_{1}$, has a substitution of (E)-3-(2,4-dimethoxy phenyl)-1-phenyl prop-2-en-1-one at 1-position of benzimidazole ring. In compound $\mathbf{3} \mathbf{h}_{\mathbf{1}}$, no substitution was observed at 1-position, while in $\mathbf{3} \mathbf{h}_{\mathbf{2}}$, the substitution of ferrocenyl at 1-position was observed. At the C-7 position, the substitution of nitrogen dioxide was observed. Compounds $\mathbf{3 e}, \mathbf{3} \mathbf{m}_{\mathbf{1 5 - 1 9 , 2 7 , 3 0}}$, and $\mathbf{3 n}$ have common substitution at C-2 and C-5 positions of benzimidazole ring. 3e has 5-(trifluoromethyl) pyridine-2-amine substitution at the C-2 position, while at C-5, it has 1-methyl piperidine substitution. While $\mathbf{3} \mathbf{m}_{\mathbf{1 5 - 1 9}}$ has chloro substitution at C-5 and ethylidene $\mathrm{N}$-(substituted) hydrazine carbothioamide at the C-2 position, and $\mathbf{3 m}_{\mathbf{2 7}, 30}$ has no substitution at the C-5 position, but at the C-2 position, it has ethylidene $\mathrm{N}$-(substituted) hydrazine carbothioamide of benzimidazole. In compound $\mathbf{3 n}$, the substitution of another benzimidazole molecule at the $\mathrm{C}-2$ position of the benzimidazole ring and formamidine substitution at the $\mathrm{C}-5$ position of the benzimidazole ring. Compounds $\mathbf{3} \mathbf{f}_{\mathbf{1 - 3}}, \mathbf{3} \mathbf{k}_{\mathbf{1 - 3}}$, and $\mathbf{3 i}$ have a substitution at $\mathrm{C}-2$ and 1-position, while $3 \mathrm{i}$ have additional substitution at C-4 and C-5. $\mathbf{3 f}_{\mathbf{1 - 3}}$ has a 2-pyridine substitution at C-2 position and substitution of acetophenone ring at 1-position of benzimidazole ring. Substitution of chloro, phenyl, and nitro group in the acetophenone ring. Compound $\mathbf{3} \mathbf{k}_{\mathbf{1 - 3}} \mathbf{3 a s}$ a benzyl substitution at the C-2 position, while it also has an acetophenone substitution at 1-position. At acetophenone, it has 1-methoxy, 3-methoxy, 4-methoxy substitutions. Compound 3i has N-cyclopropylthiophene-2-carboxamide substitution at 1-position. At the C-2 position, it has methyl substitution, while at C-4, it has 4-trifluoromethoxy group and cyano group substitution. At the C-5 position, it has a trifluoromethoxy group substituted at the benzimidazole ring. 


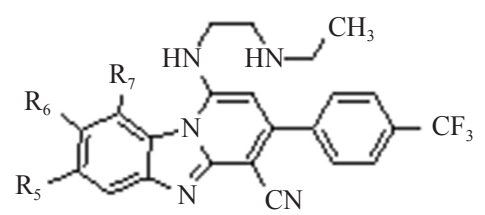<smiles>N#C/C(=C\c1ccccc1)c1nc2ccccc2[nH]1</smiles>

$3 \mathrm{~b}_{1}, \mathrm{R}=3-\mathrm{OCH}_{3}$ $3 \mathrm{~b}_{2}, \mathrm{R}=3-\mathrm{OCH}_{3}, 5-\mathrm{OCH}_{3}$ $3 \mathrm{~b}_{3}, \mathrm{R}=3-\mathrm{OCH}_{3}, 4-\mathrm{OCH}_{3}$<smiles>[R][X]c1ccc(NC(=O)c2ccc3[nH]c(-c4ccc([N+](=O)[O-])[X]4[H])nc3c2)cc1</smiles>
$3 \mathrm{c}_{2}, \mathrm{X}=\mathrm{O}, \mathrm{R}=3,4,5-\mathrm{OCH}_{3}$ $3 \mathrm{c}_{3}, \mathrm{X}=\mathrm{O}, \mathrm{R}=2,4-\mathrm{OCH}_{3}$ $3 \mathrm{c}_{4}, \mathrm{X}=\mathrm{O}, \mathrm{R}=3,4-\mathrm{OCH}_{3}$ $3 \mathrm{c}_{5}, \mathrm{X}=\mathrm{O}, \mathrm{R}=2-\mathrm{OCH}_{3}$ $3 \mathrm{c}_{6}, \mathrm{X}=\mathrm{S}, \mathrm{R}=3,4-\mathrm{OCH}_{3}$ $3 \mathrm{c}_{7}, \mathrm{X}=\mathrm{S}, \mathrm{R}=2-\mathrm{OCH}_{3}$

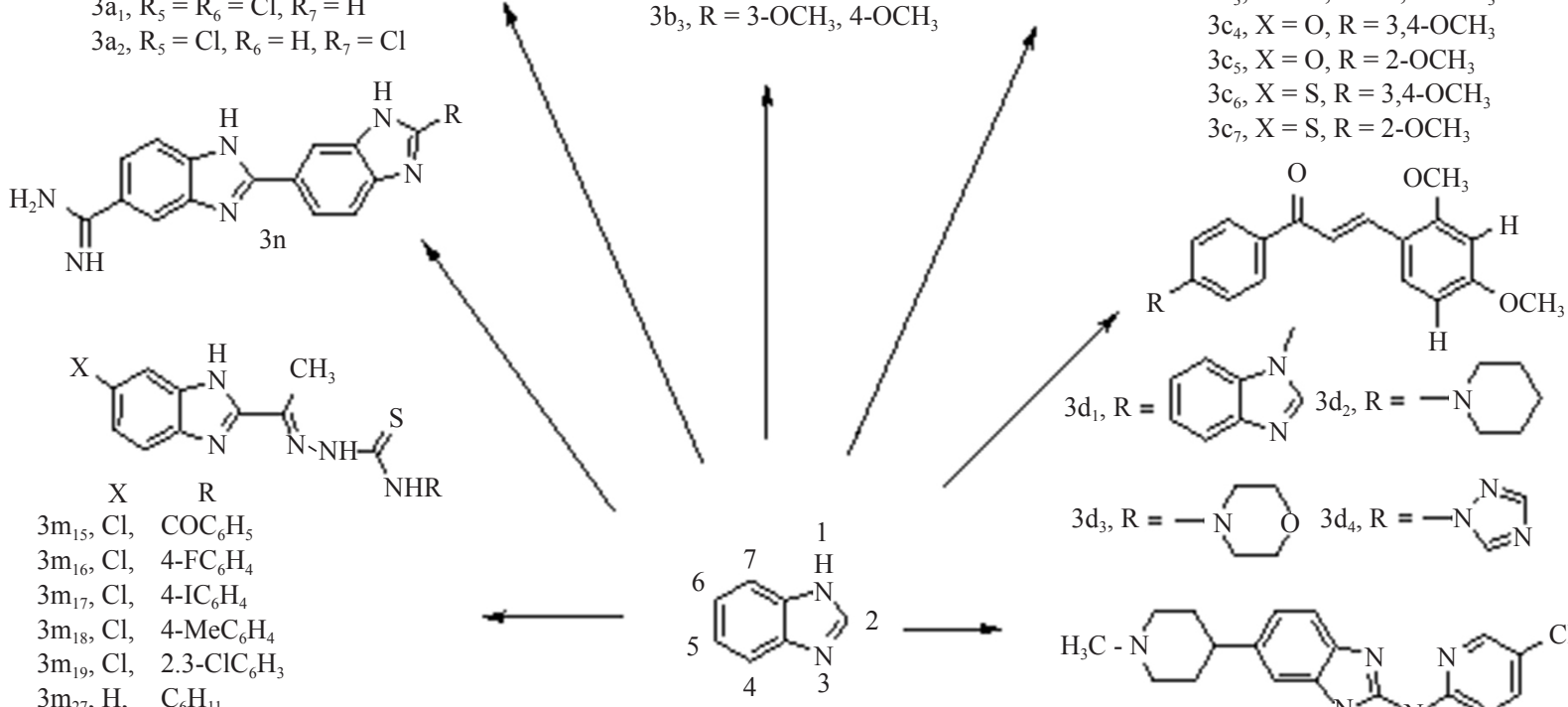

$3 \mathrm{~m}_{17}, \mathrm{Cl}, \quad 4-\mathrm{IC}_{6} \mathrm{H}_{4}$

$3 \mathrm{~m}_{18}, \mathrm{Cl}, \quad 4-\mathrm{MeC}_{6} \mathrm{H}_{4}$

$3 \mathrm{~m}_{19}, \mathrm{Cl}, \quad 2.3-\mathrm{ClC}_{6} \mathrm{H}_{3}$

$3 \mathrm{~m}_{27}, \mathrm{H}, \quad \mathrm{C}_{6} \mathrm{H}_{11}$

$3 \mathrm{~m}_{30}, \mathrm{H}, \quad 4-\mathrm{MeOC}_{6} \mathrm{H}_{4}$<smiles>[R]c1cc(C(=O)Cn2c(-c3ccccn3)nc3ccccc32)c([R])c([R])c1[R]</smiles>

$3 \mathrm{k}_{1}, \mathrm{R}_{1}=\mathrm{H}, \mathrm{R}_{2}=\mathrm{H}, \mathrm{R}_{3}=\mathrm{H}, \mathrm{R}_{4}=\mathrm{H}$

$3 \mathrm{k}_{2}, \mathrm{R}_{1}=\mathrm{H}, \mathrm{R}_{2}=\mathrm{H}, \mathrm{R}_{3}=\mathrm{OCH}_{3}, \mathrm{R}_{4}=\mathrm{H}$

$3 \mathrm{k}_{3}, \mathrm{R}_{1}=\mathrm{OCH}_{3}, \mathrm{R}_{2}=\mathrm{H}, \mathrm{R}_{3}=\mathrm{H}, \mathrm{R}_{4}=\mathrm{OCH}_{3}$<smiles>[R]C(=O)NNC(=O)c1ccc2nc(-c3[X]c([X])cc3)[nH]c2c1</smiles>

$3 \mathrm{j}_{2}, \mathrm{X}=\mathrm{O}, \mathrm{R}=\mathrm{H}$

$3 \mathrm{j}_{3}, \mathrm{X}=\mathrm{O}, \mathrm{R}=\mathrm{Ph}$

$3 \mathrm{j}_{4}, \mathrm{X}=\mathrm{O}, \mathrm{R}=3,4-\mathrm{MeOPh}$

$3 \mathrm{j}_{5}, \mathrm{X}=\mathrm{S}, \mathrm{R}=3,4-\mathrm{MeOPh}$

$3 \mathrm{j}_{6}, \mathrm{X}=\mathrm{S}, \mathrm{R}=3-\mathrm{OH}-2$-naphtyl
$1 H$-benzo $[d]$ imidazole

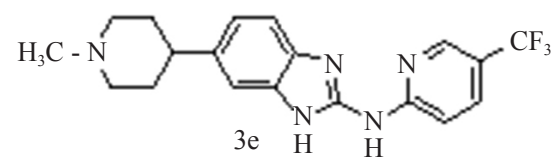

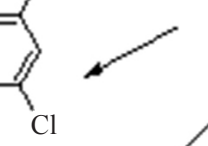
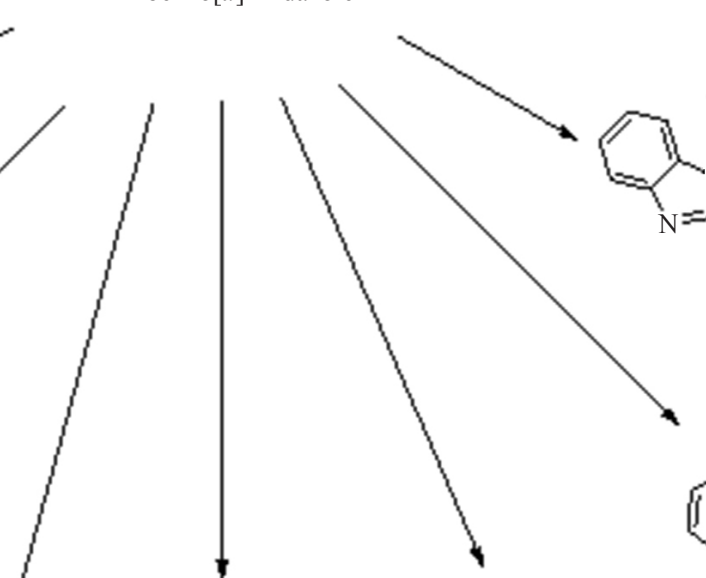

तो

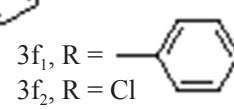

$3 \mathrm{f}_{3}, \mathrm{R}=\mathrm{NO}_{2}$<smiles>Cc1ccccn1</smiles><smiles></smiles>

$3 \mathrm{~g}, \mathrm{R}=\mathrm{N}(\mathrm{Et})_{2}$<smiles>O=C(NC1CC1)c1ccc(I)s1</smiles><smiles>[R]c1ccc2c(nc(C)n2C)c1[R]</smiles>

$\mathrm{R}_{1}$<smiles>CC(C)(C)C1(C(C)(C)C)C=CC=C1c1nc2ccc(I)cc2[nH]1</smiles>
$3 \mathrm{~h}_{1}, \mathrm{R}_{1}=\mathrm{H}, \mathrm{NO}_{2}$ $\mathrm{OC}^{\prime} \mathrm{C} \mathrm{O}$ $\mathrm{R}_{1}$<smiles></smiles>
$3 \mathrm{~h}_{2}, \mathrm{R}_{1}=\mathrm{H}, \mathrm{NO}_{2}$;<smiles>[R]Cc1ccccc1-c1ccccc1</smiles>

Figure 3. Novel benzimidazole hybrid derivatives 


\section{Future perspective}

Benzimidazole moiety has a diverse molecular target, and in medicinal chemistry, it has privileged and remarkable activities. In the current review, 14 publications were considered and more studies were needed in malaria-endemic countries. The survey of benzimidazole moiety in the future could give a unique identification in medicinal chemistry. It is expected that this information would rise to develop better moiety with boosted antimalarial properties, more stable as a potential drug/drugs candidates for preclinical and clinical studies with a novel mechanism of action to overcome the antimalarial drug resistance.

\section{Conclusion}

This comprehensive review summarizes the novel benzimidazole hybrid derivatives relating structures, SAR, and QSAR model with their related antimalarial activity. The benzimidazole ring plays a significant role in biological and pharmacological activities. Based on the evidence from in vitro, in vivo, and in silico studies, novel benzimidazole hybrid derivatives diminished the parasite's action in the liver and gametocyte stages, inhibiting heme synthesis and $\beta$-hematin formation. The novel benzimidazole hybrids derivatives bind at subsite enzymes, namely S1 (Cys42 and His174) and S2 (viz. Trp43, Leu84, Ile85, Ser149, Ala175, and Gly83), with His 67 of the enzyme and the center plasmepsin II active substrate. Future investigations of these derivatives could lead to a promising benzimidazole-based antimalarial activity in medicinal chemistry.

\section{Conflict of interest}

The authors declare no conflict of interest.

\section{Acknowledgements}

The authors are grateful for the e-resources provided by Tripura University (A Central University), Suryamaninagar, Tripura, India-799022. We are also grateful to University Grant Commission (UGC), Govt. of India, for providing Startup Grant [F. 20-2 (24)/2012 (BSR)] for newly recruited faculty and financial support. We are also acknowledging Department of Science and Technology (DST), Govt. of India for awarding DST Fast Track Scheme [NO. SB/FT/CS-150/ 2012].

\section{References}

[1] Singh, S.; Rajendran, V.; He, J.; Singh, A. K.; Achieng, A. O.; Vandana, P. A. ACS Infect Dis. 2018, 5, 184-198.

[2] Camacho, J.; Barazarte, A.; Gamboa, N.; Rodrigues, J.; Rojas, R.; Vaisberg, A. Bioorg Med Chem. 2011, 19, 2023 2029.

[3] Desai, M.; Ter Kuile, F. O.; Nosten, F.; McGready, R.; Asamoa, K.; Brabin, B.; Newman, R, D. Lancet Infect Dis. 2007, 7, 93-104.

[4] Roser, M.; Ritchie, H. Malaria. https://ourworldindata.org/malaria (accessed May 1, 2019).

[5] Papaioannou, I.; Utzinger, J.; Vounatsou, P. Sci Rep. 2019, 9, 1-9.

[6] Talapko, J.; Skrlec, I.; Alebic, T.; Jukic, M.; Vcev, A. Microorganisms. 2019, 7, 179.

[7] World malaria report 2018. World Health Organization: Geneva. https://apps.who.int/iris/bitstream/hand le/10665/275867/9789241565653-eng.pdf (accessed May 1, 2019).

[8] Phillips, M.; Burrows, J.; Manyando. C. Malaria. Nat Rev Dis Primers. 2017, 3, 17050.

[9] Tse, E. G.; Korsik, M.; Todd, M. H. Malar J. 2019, 18, 93.

[10] Antony, H. A.; Parija, S. C. Trop. Parasitol. 2016, 6, 30-41.

[11] Blasco, B.; Leroy, D.; Fidock, D. A. Nat Med. 2017, 23, 917-928. 
[12] Gaillard, T.; Madamet, M.; Tsombeng, F. F.; Dormoi, J.; Pradines, B. Malar J. 2016, 15, 1-10.

[13] Phillips, M. A.; Goldberg, D. E. Science. 2018, 362, 1112-1113.

[14] Yadav, G.; Ganguly, S. Eur J Med Chem. 2015, 97, 419-443.

[15] Sharma, S.; Abuzar, S. The benzimidazole anthelmintics-chemistry and biological activity. In Progress in Drug Research/Fortschritte Der Arznesimittelforschung/Progrès Des Recherches Pharmaceutiques; Jucker E.; Springer, 1983; pp 85-161.

[16] Gaba, M.; Mohan, C. Med Chem Res. 2016, 25, 173-210.

[17] Alamgir, M.; Black, D. S.; Kumar, N. In Bioactive Heterocycles III; Springer, Berlin, Heidelberg, 2007; pp 87-118.

[18] Dini, S.; Zaloumis, S.; Cao, P.; Price, R. N.; Fowkes, F. J.; van der Pluijm, R. W. Antimicrob Agents Chemother. 2018, 62, e01068.

[19] Leshabane, M. ACS Infec Dis. 2021, 11.

[20] Ajima, U.; Onah, J. O.; Wannang, N. N. Mediterr. J. Chem. 2019, 9, 52-64.

[21] Sahu, N. K.; Sharma, M. C.; Mourya, V.; Kohli, D. V. Arab J Chem. 2014, 7, 701-707.

[22] Ibezim, E.; Duchowicz, P. R.; Ortiz, E.V.; Castro, E. A. Chemom Intell Lab Syst. 2012, 110, 81-88.

[23] Zhang, L.; Fourches, D.; Sedykh, A.; Zhu, H.; Golbraikh, A.; Ekins, S. J Chem Inf Model. 2013, 53, 475-492.

[24] Singh, K.; Okombo, J.; Brunschwig, C.; Ndubi, F.; Barnard, L.; Wilkinson, C. J Med Chem. 2017, 60, 1432-1448.

[25] Sharma, K.; Shrivastava, A.; Mehra, R. N.; Deora, G. S.; Alam, M. M.; Zaman, M. S. Archiv der Pharmazie. 2018, $351,1700251$.

[26] Romero, J. A.; Acosta, M. E.; Gamboa, N. D.; Mijares, M. R.; De Sanctis, J. B.; Llovera, L. J. Med Chem Res. 2019, 28, 13-27.

[27] Yadav, N.; Dixit, S. K.; Bhattacharya, A.; Mishra, L. C.; Sharma, M.; Awasthi, S. K. Chem Bio Drug Des. 2012, 80, 340-347.

[28] Ramachandran, S.; Hameed, P. S.; Srivastava, A.; Shanbhag, G.; Morayya, S.; Rautela, N. J Med Chem. 2014, 57, 6642-6652.

[29] Saify, Z. S.; Azim, M. K.; Ahmad, W.; Nisa, M.; Goldberg, D. E.; Hussain, S. A. Bioorg Med Chem Lett. 2012, 22, $1282-1286$.

[30] Ndakala, A. J.; Gessner, R. K.; Gitari, P. W.; October, N.; White, K. L.; Hudson, A. J Med Chem. 2011, 54, 45814589.

[31] Toro, P.; Klahn, A. H.; Pradines, B.; Lahoz, F.; Pascual, A.; Biot, C. Inorg Chem Commun. 2013, 35, 126-129.

[32] Booker, M. L.; Bastos, C. M.; Kramer, M. L.; Barker, R. H.; Skerlj, R.; Sidhu, A. B. J Biol Chem. 2010, 285, 33054-33064.

[33] Kamil, A.; Akhter, S.; Ahmed, M.; Rizwani, G. H.; Hassan, S.; Naeem, S. Pak J Pharm Sci. 2015, 28, 2179-2184.

[34] Keurulainen, L.; Vahermo, M.; Puente-Felipe, M.; Sandoval-Izquierdo, E.; Crespo-Fernandez, B.; Guijarro-Lopez, L. J Med Chem. 2015, 58, 4573-4580.

[35] Divatia, S. M.; Rajani, D. P.; Rajani, S. D.; Patel, H. D. Arab J chem. 2014, 12, 1641-1651.

[36] Divatia, S.; Chhabaria, M. T.; Parmar, K.; Patel, H. Indian J Chem Sect B. 2016, 55B, 486-491.

[37] Worachartcheewan, A.; Nantasenamat, C.; Isarankura-Na-Ayudhya, C.; Prachayasittikul, V. Chem Pap. 2013, 67, $1462-1473$. 